\title{
Eagle syndrome causing severe stenosis of the internal carotid artery
}

\author{
Joel W. Howlett MD, Matthew Hearn MD, Cameron Bakala MD
}

Cite as: CMAJ 2021 July 19;193:E1091. doi: 10.1503/cmaj.202803

A

56-year-old man with type 2 diabetes presented to the emergency department with an acute onset of weakness in the left arm and tongue paresthesia that lasted about 5 minutes. The symptoms had recurred several times on the way to the hospital. On assessment, the patient's vital signs and neurologic examination were normal, and the initial working diagnosis was a transient ischemic attack. Computed tomography with contrast showed normal cerebrovasculature, without extracranial dissection or aneurysm; however, both styloid processes were elongated, and his right internal carotid artery was compressed between the right styloid process and the $\mathrm{C} 1$ transverse process (Figure 1A; Appendix 1, available at www.cmaj.ca/ lookup/doi/10.1503/cmaj.202803/tab-related-content).The imaging and clinical presentation were consistent with Eagle syndrome, and we were consulted for urgent surgical management.

We removed the right styloid via a transcervical approach (Figure 1B), and postprocedure angiography showed a widely patent internal carotid artery (Appendix 1). The patient made a full recovery and no further intervention was required.

Eagle syndrome, named after surgeon Watt Eagle, is an uncommon compressive syndrome related to an elongated styloid process (> $30 \mathrm{~mm}$ ), an anatomic variant in $4 \%$ of the population. ${ }^{1}$ Its presentation is often subtle and includes dysphagia, oropharyngeal fullness, headaches, cervicofacial pain and temporal mandibular joint pain caused by impingement of the styloid process on cranial nerves VII, IX or X, or the sympathetic plexus. Eagle syndrome can also result from compression of the internal carotid artery, as in our patient. Patients often report a clear relation between symptoms and head position..$^{1-3}$ Clinical examination should include a cranial nerve assessment and palpation of the neck and tonsillar fossa for a medialized bony structure. Computed tomography angiography may help to clarify
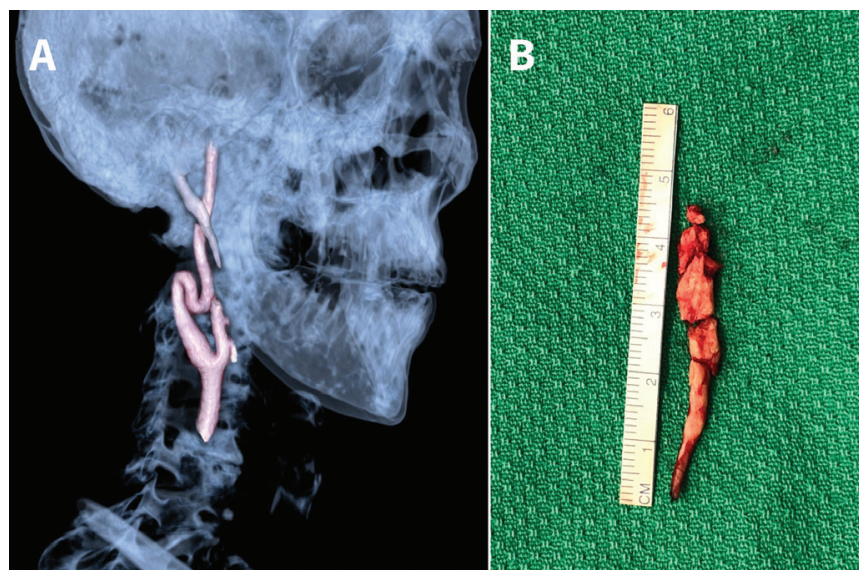

Figure 1: (A) Three-dimensional computed tomography (CT) reconstruction of the skull of a 56-year-old man with weakness in the left arm and tongue paresthesia showing elongation of the right styloid $(47 \mathrm{~mm})$ causing compression of the right internal carotid artery. (B) Right styloid after resection measured $45 \mathrm{~mm}$ (normal $20-30 \mathrm{~mm}$ ). ${ }^{1}$

the diagnosis. Patients with pain may be managed conservatively with nonsteroidal anti-inflammatory drugs, whereas surgical intervention is reserved for persistent symptoms, vascular compromise or neurologic sequelae. ${ }^{1}$

\section{References}

1. Galletta K, Siniscalchi E, Cicciù M, et al. Eagle syndrome: a wide spectrum of clinical and neuroradiological findings from cervico-facial pain to cerebral ischemia. J Craniofac Surg 2019;30:e424-8.

2. Farhat $\mathrm{HI}$, Elhammady MS, Ziayee $\mathrm{H}$, et al. Eagle syndrome as a cause of transient ischemic attacks. J Neurosurg 2009;110:90-3.

3. Ogura T, Mineharu Y, Todo K, et al. Carotid artery dissection caused by an elongated styloid process: three case reports and review of the literature. NMC Case Rep J 2014;2:21-5.

\section{Competing interests: None declared.}

This article has been peer reviewed.

The authors have obtained patient consent.

Affiliations: Division of Otolaryngology Head and Neck Surgery, Department of Surgery (Howlett, Hearn, Bakala), University of British Columbia, Vancouver, BC; Division of
Otolaryngology - Head and Neck Surgery (Hearn, Bakala), Kelowna General Hospital, Kelowna, BC

Content licence: This is an Open Access article distributed in accordance with the terms of the Creative Commons Attribution (CC BY-NC-ND 4.0) licence, which permits use, distribution and reproduction in any medium, provided that the original publication is properly cited, the use is noncommercial (i.e., research or educational use), and no modifications or adaptations are made. See: https://creativecommons.org/ licenses/by-nc-nd/4.0/

Correspondence to: Joel Howlett, joel.howlett@alumni.ubc.ca 